\title{
The view of school management beyond the institutional framework: perceptions about their own performance and family participation in school
}

\author{
O olhar da gestão escolar para além do marco institucional: percepções \\ da gestão escolar sobre a atuação e a participação familiar na escola
}

\section{La mirada de la gestión escolar más allá del marco institucional: percepciones sobre su propio desempeño y participación familiar en la escuela}

\author{
Valdirene Eliane Bailon de Souza ${ }^{1}$ iD, Rita Márcia Andrade Vaz de Mello ${ }^{1}$ iD, \\ Maria de Lourdes Mattos Barreto ${ }^{1}$ iD
}

\author{
${ }^{1}$ Universidade Federal de Viçosa, Viçosa, Minas Gerais, Brasil. \\ Autor correspondente: \\ Valdirene Eliane Bailon de de Souza \\ Email: valdirene.goncalves@yahoo.com.br
}

Como citar: Souza, V. E. B., Mello, R. M. A. V., \& Barreto, M. L. M. (2021). The view of school management beyond the institutional framework: perceptions about their own performance and family participation in school. Revista Tempos e Espaços em Educação, 14(33), e16085. http://dx.doi.org/10.20952/revtee.v14i33.16085

\begin{abstract}
In this study, we analyzed the relationship between the management team of a State School in Minas Gerais and the families of the students, identifying perceptions about their own performance and the participation of families in the institutional scope. To this end, the theoreticalmethodological axis is characterized by a case study, with a descriptive approach and a qualitative approach, based on a corpus consisting of information from seven Basic Education Specialists (BSE). Thus, we found that the management team, in general, admits the essentiality of family participation at the institutional level. However, according to the findings of this research, conflicting situations are evidenced between school members and family members/guardians of students, which demonstrates the constant need for school debates on interpersonal relationships, even with the possibility of stirring up controversies and causing confrontations of ideas, given the need to put democratic guiding principles into practice, through communicability.
\end{abstract}

Keywords: Palavra um. Palavra dois. Palavra três. Palavra quatro. Palavra cinco.

\section{RESUMO}

Neste estudo, analisamos a relação entre a equipe gestora de uma Escola Estadual de Minas Gerais e as famílias dos educandos, identificando percepções sobre a própria atuação e a participação das famílias no âmbito institucional. Para tanto, o eixo teórico-metodológico é caracterizado pelo 
estudo de caso, com abordagem de cunho descritivo e enfoque qualitativo, pautando-se em um corpus constituído por informações de sete Especialistas da Educação Básica (EEB). Assim, verificamos que a equipe gestora, em geral, admite a essencialidade da participação familiar no âmbito institucional. Todavia, conforme achados da presente pesquisa, são evidenciadas situações conflituosas entre os membros escolares e os familiares/responsáveis pelos educandos, o que demonstra a necessidade constante de debates escolares sobre as relações interpessoais, mesmo com a possibilidade de incitar polêmicas e causar confrontos de ideias, haja vista a necessidade de se colocar em prática os princípios norteadores democráticos, por meio da comunicabilidade.

Palavras-chave: Diálogo democrático. Família. Gestão escolar.

\section{RESUMEN}

En este estudio, analizamos la relación entre el equipo directivo de una Escuela Pública en Minas Gerais y las familias de los estudiantes, identificando percepciones sobre su propio desempeño y la participación de las familias en el ámbito institucional. Para ello, el eje teórico-metodológico se caracteriza por un estudio de caso, con enfoque descriptivo y enfoque cualitativo, a partir de un corpus conformado por información de siete Especialistas en Educación Básica (BSE). Así, encontramos que el equipo directivo, en general, admite la esencialidad de la participación familiar a nivel institucional. Sin embargo, de acuerdo con los hallazgos de la presente investigación, se evidencian situaciones conflictivas entre los miembros de la escuela y los familiares / tutores de los estudiantes, lo que demuestra la constante necesidad de debates escolares sobre las relaciones interpersonales, incluso con la posibilidad de suscitar controversias y provocar enfrentamientos de ideas, dada la necesidad de poner en práctica los principios rectores democráticos, a través de la comunicabilidad.

Palabras clave: Diálogo democrático. Familia. Gestión escolar.

\section{INTRODUÇÃO}

Neste estudo, objetivamos analisar a relação da equipe gestora de uma Escola Estadual de Minas Gerais com as famílias dos educandos, captando percepções sobre a própria atuação e a participação das famílias no âmbito institucional.

A equipe gestora de uma escola tem como função administrar aspectos físicos, administrativos e pedagógicos da instituição. Sob essa perspectiva, torna-se essencial manter um ambiente propício para a aprendizagem dos educandos, compartilhar as metas entre os envolvidos e facilitar o trabalho coletivo, entre outras estratégias para o desenvolvimento laboral dinâmico e eficaz (Oliveira, 2015).

Dessa forma, a escola pode contar com a colaboração de familiares ou de responsáveis pelos educandos. De acordo com Oliveira e Paes de Carvalho (2018), essa participação favorece o aprendizado efetivo dos alunos, promovendo um significativo desempenho discente, já que o ambiente escolar se mostra favorável ao ensino e à aprendizagem. Contudo, vale advertir que, mesmo diante dessas evidências positivas, poucas ações têm sido implementadas no meio educacional, para que os familiares se sintam parte do processo educacional dos filhos (Oliveira; Paes ee Carvalho, 2018).

Libâneo (2013) enxerga a relação entre família e escola como um desafio para a maioria das instituições de ensino, mesmo admitindo os diversos benefícios que podem ser alcançados a partir desse vínculo. Para o autor, falta clareza nos documentos a respeito da participação familiar no espaço escolar, ao citar especificamente a função da equipe gestora - o gestor escolar é o principal regente das ações no interior da instituição. Assim, para que haja a transformação na realidade escolar e a própria participação familiar, devem ocorrer mudanças no processo administrativo organizacional, a começar pela postura dos gestores e de sua equipe, os quais devem criar mecanismos que possibilitem o entrosamento das famílias nas ações/decisões educacionais. 
Nesse sentido, para o cumprimento dos objetivos propostos, realizamos o estudo de caso, sob abordagem de cunho descritivo e enfoque qualitativo, a partir de um corpus composto por informações de sete Especialistas da Educação Básica (EEB). De forma sintetizada, a pesquisa possui características, propriedades ou das relações existentes em certo grupo ou realidade específica (GIL, 2008), que, nesse caso, é em uma instituição escolar.

Para além da parte introdutória, estruturamos o conteúdo em três seções. Na primeira parte, apresentamos os dados da escola e dos sujeitos da pesquisa; posteriormente, descrevemos os resultados e a interpretação dos subsídios obtidos, relacionando-os à literatura de autores(as) que suscitam aspectos do ambiente escolar; por fim, tecemos as considerações finais sobre o estudo.

\section{METODOLOGIA}

\section{A escola e os sujeitos}

A Escola Estadual pesquisada está situada na cidade de Viçosa, Minas Gerais. A escolha por essa instituição pode ser justificada pelo número significativo de alunos/as (988), tendo sido considerada, por décadas, a maior instituição pública do município, ao atender estudantes viçosenses e moradores de cidades vizinhas (IBGE, 2019).

Dessa forma, em busca da análise e discussão do relacionamento entre equipe gestora e familiares dos educandos, consideramos pertinente especificar os sujeitos da pesquisa. Para aplicação dos questionários online, selecionamos sete (07) interlocutores da gestão, composta por um(a) diretor(a), dois(duas) vice-diretores(as) e quatro supervisores(as) (sendo dois de cada turno de ensino). É importante ressaltar que, antes da aplicação dos questionários, ocorreu uma conversa com a gestora da respectiva instituição sobre a melhor forma de disponibilizar o link para os sujeitos participantes. Assim, antes de dar início à coleta de dados com o questionário virtual, foi inserido um Termo de Consentimento Livre e Esclarecido (TCLE), composto por uma página de esclarecimento sobre a pesquisa, além da solicitação de autorização para o uso dos dados fornecidos pelos participantes.

O questionário designado à equipe gestora foi composto por 21 questões, sendo 14 fechadas e sete abertas, obtendo o retorno dos sete participantes da escola (Especialistas da Educação Básica - EEB). O tempo médio para preenchimento do documento online foi de $15 \mathrm{~min}$. Nos questionários, buscamos averiguar a percepção da realidade sociocultural da escola e dos membros desse contexto, bloqueando "a violência doce, invisível, desconhecida, não percebida como arbitrária, e, portanto, legitimada" (Bourdieu, 1983, p. 209). Em linhas gerais, primamos pelo caminho investigativo, cujos instrumentos metodológicos serviram de apoio para o levantamento dos dados, evidenciando, assim, possíveis contribuições das relações dispostas no âmbito escolar.

Durante a análise e discussão da presente pesquisa, a instituição recebe o nome fictício "Escola Estadual Lírio azul". A escolha ocorreu pelo fato do lírio, na respectiva cor, significar segurança, bons sentimentos e confiança, sendo estas qualidades que procuramos e almejamos em um ambiente escolar. Tal decisão está em consonância aos princípios da Resolução nํ466/2012, do Conselho Nacional de Saúde do Ministério de Saúde, Brasília/DF, para o regulamento de pesquisas que envolvem seres humanos.

Para melhor conhecimento dos profissionais da E. E. Lírio Azul, apresentamos, no Quadro 1, algumas características que identificam cada um desses sujeitos. Lembrando que os nomes são meramente fictícios, com as iniciais para identificação do cargo: G - Gestor(a), VG - Vice-Gestor(a) e S-Supervisor(a).

Tabela 1. Perfil dos gestores. 


\begin{tabular}{|c|c|c|c|}
\hline Nome & Idade & $\begin{array}{c}\text { Tempo de } \\
\text { experiência na } \\
\text { área }\end{array}$ & Formação acadêmica \\
\hline G - Aurora & 54 & 13 & Graduada em História com Especialização na área \\
\hline S - Luna & 27 & 1 ano e 6 meses & Graduada em Pedagogia com Mestrado na área \\
\hline S - Bruna & 26 & 1 ano e 8 meses & Graduada em Pedagogia com Especialização na área \\
\hline S- Elsa & 56 & 27 anos & Graduada em Pedagogia com Especialização na área \\
\hline S - Lara & 39 & 5 anos & Graduada em Pedagogia com Especialização na área \\
\hline VG- Ana & 37 & 6 anos & Graduada em Pedagogia com Especialização na área \\
\hline VG - Naldo & 39 & 11 anos & Graduado em História com Especialização na área \\
\hline
\end{tabular}

Fonte: Elaborado pela pesquisadora (2020).

Conforme informações disponibilizadas no Quadro 1, a faixa etária dos profissionais está entre 30 e 40 anos, o que representa $42,9 \%$ do total, seguido de $28,6 \%$ para os participantes com idade entre 20 e 30 anos, e a mesma porcentagem para a faixa de 51 e 60 anos (28,6\%). Notamos, assim, em um cenário de trabalho democrático, que a idade dos gestores é bastante heterogênea, fato que pode contribuir para troca de experiências e de opiniões.

Em relação ao tempo de atuação, 66,7\% possuem experiência acima de cinco anos na área, havendo somente dois dos profissionais (33,3\%) com tempo inferior a dois anos. Outro dado observado é que $71,5 \%$ são licenciados(as) em Pedagogia e $28,5 \%$ licenciados(as) em História. No total da equipe, 6 (seis) possuem especialização $(85,7 \%)$ e somente1 (uma) possui Pós-Graduação Stricto Sensu (Mestrado) (14,3\%).

Por meio dos dados supracitados, atestamos a recorrência de pedagogos ocupando cargos de gestão. Essa situação trivial é fundamentada pelo art. 64 da LDB/1996, que vem a consentir a atuação nas áreas de administração, planejamento, inspeção, supervisão e orientação educacional (educação básica) para os profissionais formados em Educação, em Pedagogia, ou com PósGraduação nessas áreas, a critério da instituição de ensino, sendo garantida, nessa formação, a base comum nacional (Brasil, 1996).

Sobre essa questão, Libâneo e Pimenta (2002) expõem a importância do pedagogo no papel de gerência em instituições de ensino. Para os autores, tal atuação tem como objetivo propiciar a melhoria da qualidade do ensino, otimizando a oferta da educação para a população, já que suas atribuições estão imbricadas no setor pedagógico escolar.

\section{RESULTADOS E DISCUSSÃO}

\section{Percepções da gestão escolar sobre a própria atuação e a participação familiar}

No presente trabalho, expressamos o posicionamento da equipe gestora sobre o dia a dia laboral, incluindo as perspectivas dessa área de atuação. Sob esse viés, as perguntas do questionário foram desenvolvidas com o intuito de incitar a reflexão dos referidos profissionais, de modo a analisar, ainda, as relações praticadas no ambiente de trabalho, especificamente o vínculo mantido com as famílias dos educandos.

Dessa forma, iniciamos a pesquisa com o tema Projeto Político Pedagógico (PPP) da instituição, documento cujo objetivo é ressignificar as práticas educativas sob a perspectiva humanizadora, de forma semelhante à educação proposta pelo grande educador Paulo Freire, este que, por sua vez, defende o atendimento às necessidades e o respeito à diversidade dos sujeitos envolvidos na ação educativa. Nessa perspectiva, questionamos se os pais ou responsáveis pelos educandos participam da construção do PPP, conforme preconizado pelo documento em questão (PPP). 
Todos os profissionais afirmaram que, via de regra, o convite é feito aos familiares. No entanto, quando indagados sobre essa presença, 57,1\% classificam tal atuação como insatisfatória e 42,9\% consideram razoável. Diante das respostas e da análise de alguns documentos disponibilizados no site da SEEMG, verificamos que o PPP não apresenta uma periodicidade exata para alterações e acréscimos, sendo a reformulação realizada conforme as necessidades surgidas durante o ano letivo. Segundo Trindade et al. (2015):

O projeto não é algo que é construído e em seguida arquivado ou encaminhado às autoridades educacionais como prova do cumprimento de tarefas burocráticas. Ele é construído e vivenciado em todos os momentos, por todos os envolvidos com o processo educativo da escola, contribuindo assim para uma escola ativa, uma escola democrática. [...] Planejar e construir um projeto político pedagógico é ter compromisso com uma educação de qualidade e participativa, é a união entre escola e comunidade, comunidade e escola, pois ambos são indissociáveis. É trilhar um caminho com foco na aprendizagem, participar de opiniões e responder os questionamentos (Trindade et al., 2015, p. 4).

Portanto, a participação não tão favorável, como a descrita pelos profissionais, resulta na dificuldade de funcionamento dos mecanismos institucionais.

Acreditamos que a presença insatisfatória desses membros da comunidade escolar pode ser oriunda da falta de compreensão de sua participação, já que os pais, muitas vezes, desconhecem sua importância, ou, no mínimo, subestimam o exercício desse dever.

Ao serem questionados sobre a porcentagem média de participação dos familiares na escola, os resultados demonstram a margem de $0 \%$ a $25 \%$, o que configura uma baixa presença. Esse dado faz com que transitemos por algumas discussões, do porquê dessa ausência, uma vez que tanto a família quanto a escola passam, e continuam passando, por transformações em sua estrutura (Nogueira, 2006; Szymanzki, 2011).

Nesse sentido, precisamos desmitificar que essa omissão seja justificada pela falta de vontade dos familiares. É preciso considerar, como preconizam Bourdieu \& Passeron (1992), que cada grupo social desempenha determinada posição em uma estrutura social, gerando um sistema específico de disposições para cada ação e atitude cotidiana. No caso da (não) participação parental, um condicionante importante seria a questão econômica. Essa afirmativa é fruto de experiência própria, em relação aos meus pais e à minha atuação como docente em escola pública, enquanto pesquisadora do campo educacional.

Na presente discussão, não podemos ignorar o patriarcado, que se tornou tema frequente na literatura para compreender e fundamentar o contexto nacional (e também internacional). De acordo com Saffioti (2004), antigamente, a mulher era designada a cuidar dos filhos e da casa, enquanto o homem buscava o sustento trabalhando fora. Hoje, ambos são os responsáveis pela manutenção do lar; inclusive, há situações em que a mulher é a única provedora econômica.

Diante desse tipo de mudança, é fundamental considerar/compreender os aspectos que forçam as famílias a não acompanharem a vida escolar dos filhos. Será que pedem ao tio(a), vizinho(a), padrinho/madrinha, ou aos avós para comparecerem em reuniões e eventos escolares? Será que esses pais não solicitam alguma flexibilização nos horários para conseguirem comparecer à escola? A visão de participação no âmbito escolar é entendida pelos profissionais somente com a presença efetiva dos pais? Tais indagações são necessárias para sugerir soluções que estimulem a participação dos familiares em eventos, reuniões e em tomadas de decisão relacionadas ao ensino dos alunos/filhos.

Reafirmamos que o objetivo da presente pesquisa não é compreender a baixa aderência familiar na escola, mas esse breve apontamento se fez necessário diante do que vivenciamos como expectativas sobre as famílias. Em muitos casos, os familiares se sentem frustrados por não estarem 
inseridos no espaço escolar, ausência esta justificada por atribuições laborais. Adicionalmente, faltam recursos econômicos e até culturais para se conquistar um acompanhamento favorável.

Diante do exposto, observamos que os familiares, em geral, tendem a seguir o que Bourdieu (2001) intitula como "liberalismo" em relação à educação dos filhos. Nogueira e Nogueira (2002) corroboram com a afirmação de que essas famílias, de recursos reduzidos, apresentam a tendência natural de oferecer um retorno mínimo com os títulos escolares dos filhos. Segundo Bourdieu (2001), esse liberalismo expressa a falta de acompanhamento de modo contínuo, sem cobranças de sucesso escolar dos educandos, configurando um caminho escolar mais breve, o que, por sua vez, agiliza a entrada no mercado de trabalho (inserção profissional), em prol da aquisição de renda familiar.

Com relação ao tipo de convite feito para participação efetiva dos familiares nas decisões e na realização de eventos escolares, buscamos conhecer a forma e a frequência de invitamento adotada pela instituição. As respostas foram disponibilizadas na Tabela 1, a seguir.

Tabela 1. Tipo de convite voltados aos familiares.

\begin{tabular}{cccccc}
\hline $\begin{array}{c}\text { Órgãos } \\
\text { Colegiados }\end{array}$ & $\begin{array}{c}\text { Reuniões } \\
\text { administrativas }\end{array}$ & $\begin{array}{c}\text { Reuniões } \\
\text { pedagógicas }\end{array}$ & $\begin{array}{c}\text { Eventos } \\
\text { escolares }\end{array}$ & $\begin{array}{c}\text { Problemas } \\
\text { indisciplinares }\end{array}$ & $\begin{array}{c}\text { Receber } \\
\text { elogios }\end{array}$ \\
\hline $31,4 \%$ & $28,6 \%$ & $100 \%$ & $85,7 \%$ & $71,4 \%$ & $0 \%$ \\
\hline
\end{tabular}

Fonte: Elaborada pela pesquisadora (2020).

Os chamados mais frequentes da rotina escolar constituem as reuniões pedagógicas (100\%), os eventos escolares $(85,7 \%)$ e os problemas indisciplinares $(71,4 \%)$. Para compreender esses dados, resgatamos as considerações de Paro (2011) que elucida a falsa ilusão de presença e de gestão democrática, conforme o centralismo da administração e a distribuição de poderes. Muitos obstáculos resultam na ausência de canais apropriados e mais atrativos, o que favoreceria a participação de todos os segmentos, inclusive o familiar. Paro (2011) salienta, também, a importância dos órgãos colegiados dentro da instituição de ensino, tais como a Associação de Pais e Mestres (APM). Nesse caso, os referidos órgãos são primordiais para o envolvimento dos pais na condução da escola, conquistando, assim, melhorias no sistema público de ensino (atualmente aquém das necessidades sociais). Contudo, notamos que os órgãos colegiados são responsáveis por apenas $31,4 \%$ dos convites direcionados às famílias.

É interessante observar que as convocações, em geral, tratam de situações em que os pais devem lidar com má conduta/comportamento ou baixo desempenho acadêmico dos filhos; são raras as situações que enaltecem os alunos de boa conduta, como, por exemplo, convite para escutar elogios ou apresentar a evolução satisfatória desses educandos. Luck (2014) sobre a questão afirma que a participação pode ocorrer de formas diferenciadas nas escolas, dependendo das condições internas da instituição e das famílias que se envolvem nesse espaço.

Ainda, no sentido da inserção familiar na instituição, questionamos de que forma os profissionais avaliam a importância da participação dos familiares no contexto escolar dos alunos. Dos sete funcionários(as), apenas 5 (cinco) explicaram sobre o valor da inclusão, mesmo a questão sendo clara a respeito do assunto. Como as respostas foram bastante sucintas, com, no máximo, duas palavras, descrevemos aquelas que expressaram uma visão mais detalhada:

O aluno melhora muito o desempenho quando a família acompanha seu desenvolvimento. 0 suporte da família e o diálogo com a escola são fundamentais no crescimento do estudante (G - Aurora).

A mudança dos estudantes é visivelmente melhor quando os pais estão presentes na escola, tanto em relação à aprendizagem, quanto ao comportamento. Os pais que não acompanham a 
vida escola dos filhos acabam deixando de lado, também, os valores morais das crianças, o que faz com que ela seja mais agressiva, indisciplinar, e com menor aproveito dos estudos ( $\mathrm{S}$ - Luna).

Quando a família se envolve com os assuntos escolares de seu filho, ele se sente motivado a avançar nos estudos, melhorando, sem dúvida, a autoestima e a aprendizagem do aluno ( $\mathrm{S}-$ Bruna).

A educação sem a participação da família não atinge seu objetivo. Família e escola precisam trabalhar juntos para obtenção do êxito ( $S$ - Lara).

A família está participando cada vez menos da vida de seus filhos, terceirizando o papel da construção do indivíduo e negligenciando a construção afetivo emocional. Acredito que, se um dia conseguimos uma participação mais efetiva dos familiares, ela com certeza irá refletir em boas condições de desenvolvimento e de aprendizagem para os filhos (VG - Naldo).

A partir dos relatos, que reforçam a visão positiva da participação familiar na vida escolar dos filhos(as), atestamos que o desempenho desses educandos é algo bastante notório nos estudos sobre sociologia da educação, principalmente no que se depreende das obras de Bourdieu (1983; 2001).

Bourdieu e Passeron (1992) e Setton (2002; 2010) abordam o incentivo do fator social no desempenho escolar, ao confirmarem que o rendimento dos educandos está associado à dimensão da classe à qual pertence. Nesse sentido, não podemos concluir que as famílias desprovidas de capital econômico e cultural não se interessam pela vida escolar dos filhos. Como agravante, a escola pouco atua para desmistificar essa violência simbólica, o que faz perpetuar o problema do distanciamento entre família e escola.

Em relação às mudanças que ocorreram no processo de ensino e aprendizagem das escolas estaduais de Minas Gerais (MG) ${ }^{1}$, em detrimento da pandemia da Covid-19 instaurada no ano de 2020, a equipe gestora foi indagada sobre a forma adotada para manter/estimular o vínculo e a participação familiar nesse cenário de estudo remoto. Descrevemos, a seguir, alguns excertos que se destacaram:

Antes coadjuvante no processo de ensino, agora os pais tornaram-se atores principais nessa educação. Os filhos passaram a depender mais da ajuda, uma vez que o papel do professor acabou ficando um pouco mais retido nesse processo. É comum receber várias reclamações e questionamentos quanto a efetividade desta nova forma de trabalho, mas, devido à gravidade da situação, esta acabou sendo a única alternativa viável no momento. Portanto, pode-se dizer que os pais assumiram uma responsabilidade quase total no processo de ensino e aprendizagem, especialmente para os alunos da Educação Infantil e Ensino Fundamental (S Luna).

Uma parcela tem como ajudar os filhos, outra parcela não tem como, por não ter conhecimento das tecnologias que envolvem o processo ( $S$ - Bruna).

Sei que é um momento nunca vivenciado por nós, mas penso que a participação auxilia todo processo de aprendizado e os pais são os facilitadores. A família continua delegando o papel de

\footnotetext{
${ }^{1}$ O Estado de Minas Gerais iniciou o Regime de Estudo não Presencial (REANP) no dia 18 de maio de 2020. Para esse regime de estudo, foram estruturados três recursos que funcionam de maneira complementar: o Plano de Estudo Tutorado (PET), o aplicativo Conexão Escola e o programa de TV “Se Liga na Educação" que é exibido pelo canal da Rede Minas ou pelo YouTube, além das redes sociais e do site da Secretaria Estadual de Educação (SEE), que também contribuem para a integração das ações. Disponível em:<https://estudeemcasa.educacao.mg.gov.br/pets>. Acesso em: 30 out. 2020.
} 
educar a escola, mesmo com as mudanças acreditam que em algum momento a escola terá que sanar essa defasagem. Os educandos encaram esse momento como férias estendidas ( $\mathrm{S}$ - Lara).

Tem sido pouco, pra não dizer nula. Avalio como deficiente, pois os pais não estão se informando sobre o novo formato de ensino e estão deixando seus filhos negligenciarem os seus estudos (VG - Naldo).

Mediante à situação relatada, é possível percebermos que o momento de pandemia, que se instaurou no Brasil e no mundo, traz como consequência a convocação da família para atuar no ensino, conforme relatos das supervisoras Luna e Bruna. Contudo, a generalização desse processo não abarca a diversidade brasileira de contextos e de famílias - há vários entraves que dificultam o acompanhamento do ensino ofertado à distância, visto que muitos não possuem acesso à internet e desconhecem os dispositivos que poderiam agregar ao processo de ensino e aprendizagem, durante esse período de distanciamento social.

A pandemia só exaltou as discrepâncias educacionais, uma vez que os indivíduos que conhecem os protocolos estabelecidos, que possuem poder aquisitivo e domínio da tradição das teorias vigentes, são os mais propícios a inovar e a estabelecerem outras regras para a continuidade da educação dos filhos, sem prejuízos no processo de ensino e aprendizagem (BOURDIEU, 2001).

No que tange às desigualdades educacionais, muitas famílias e educandos encontram-se frustrados diante dos impactos negativos da Covid-19, assim como os docentes em geral. Muitos professores foram impelidos a atuar no teletrabalho sem sequer ter formação específica e, ou, estrutura para isso. A esse respeito, o sociólogo e professor Ruy Braga (2020) pontua que o ambiente doméstico não deve favorecer a produtividade do trabalho, visto que os profissionais em geral não se prepararam para trabalhar em casa, ao lado das atividades mais tradicionais do cotidiano. Por outro lado, há debates por parte do governo para que haja uma nova organização espacial no setor público, a fim de ampliar e normatizar a adoção do teletrabalho home office no setor público. Essa vontade por parte do governo significa, consequentemente, economia e corte aos cofres públicos, uma vez que o atual governo é autor da reforma administrativa alvitrada pela Proposta de Emenda à Constituição (PEC) 32 de 2020, que precariza o emprego público e praticamente acaba com a estabilidade dos futuros servidores, em nome de uma almejada redução de gastos, que é contraditoria ao deixar de fora as carreiras que mais gastos e previlégios possuem (BRAUNERT \& BRIDI, 2020).

Antunes (2020) pondera claramente a mesma situação, ao expor que os impactos negativos para serviços que visam assegurar direitos (como a educação) são muitos, visto que a maioria dos profissionais não estão acostumados com o ensino à distância, e essa falta de interação física - entre educando e docente - leva a uma forte tendência de mecanização da educação e de padronização de processos que deveriam ser mais individualizados.

Durante a organização das questões do questionário, pensamos que, como se trata da relação entre familiares e escola, os profissionais da gestão deveriam narrar situações em que sofreram algum tipo de ameaça ou de constrangimento. Se sim, pedimos para eles descreverem tal circunstância. As situações relatadas foram:

Houve uma postura inadequada do professor e, como gestora, tomamos as providências cabíveis. No entanto, a família acreditava que podíamos usar de punições que não nos cabe e ameaçou nos denunciar aos órgãos competentes. Outro exemplo: ao usar de posturas pedagógicas para resolver um problema com o filho, a família discordou e ameaçou chamar a polícia (S - Luna).

A informação recebida não era verídica, o que gerou fala áspera, a qual foi sanada após conversa (S-Bruna). 
Intimidação e ofensas à minha moral, o que causou grande desconforto. (S - Lara).

Ao chamar a atenção do aluno na secretaria de forma respeitosa, devido a algumas ações que vinha realizando na escola, fui surpreendido no outro dia pela família com palavras injuriosas e ofensivas. Se um outro professor não tivesse intervindo, eu poderia ter sofrido agressões físicas (VG - Naldo).

Do total de entrevistados, 57,2\% confirmaram já terem sofrido algum tipo de agressão verbal de familiares. Ressalvados esses registros, percebemos que a escola constitui um espaço para eclosão dos problemas vivenciados pelos indivíduos na sociedade, nesse caso, as famílias dos educandos. A mesma concepção é reforçada por Gonçalves e Sposito (2002) e Schilling (2004), autores que relatam dificuldades, sobretudo no que diz respeito aos aspectos econômicos que ocasionam desigualdades sociais, e isso repercute, de certo modo, no cotidiano das escolas. Para Sposito (2002), analisar as relações que geram condutas violentas no interior da instituição escolar é um grande desafio para os pesquisadores, uma vez que demanda a compreensão de processos mais abrangentes que (re)produzem a violência como um componente da vida social contemporânea.

Se a escola se torna uma válvula de escape para os sujeitos que ali estão inseridos e são convidados a participarem, Cury (2002, p. 23) conclui que esse espaço "deve ser o lugar onde os conflitos necessitam se resolverem pela palavra". Nesse sentido, o papel da gestão se torna de grande relevância, pois o gestor pode (e deve) colocar em ação os princípios da gerência democrática, por meio do diálogo e do seu conhecimento, agindo com competência, responsabilidade e parceira para superação das desigualdades.

Os excertos acima apresentados incitaram outro questionamento - o que mais incomoda os profissionais participantes, dentro do espaço escolar. Assim, foram proferidas as seguintes alocuções:

Acho que a falta de recursos financeiros muitas vezes limita algumas metodologias e práticas pedagógicas, além de falas comprometedoras não verídicas entre a equipe (G- Aurora).

A competição interna por parte da equipe, mesmo que para algo que não há o que ganhar. Resumindo, nessa competição, todos saem perdendo, pois não há união. E está mais do que comprovado que o trabalho em equipe gera bons frutos, mas infelizmente essa regra não se aplica a diversos casos (S - Luna).

Desde os estágios realizados na época da licenciatura em Pedagogia, a falta de acolhimento no ambiente escolar sempre me incomodou, sendo que nada mudou quando iniciei a profissão. Os problemas podem ser muitos, mas, quando há união, reciprocidade e vontade de compartilhar o que se sabe, tudo se torna mais fácil ( $S$ - Lara).

Falta de união entre os colegas de trabalho, sendo que essa situação desgasta muito o emocional e compromete todo o trabalho, além do desinteresse das pessoas por qualquer tipo de ação ou projeto que venha se propor na escola ( $S$ - Bruna).

Falta da participação familiar na vida escolar do educando, falta de recurso e falta de ética entre os colegas (VG - Naldo).

De acordo com os relatos, com destaque para os dizeres da gestora Aurora e do vice-gestor Naldo, faltam recursos financeiros para instituição, o que acarreta, de certo modo, algumas dificuldades para o trabalho pedagógico e administrativo. 
Vale pontuar que somente o VG Naldo relatou que a não participação familiar no contexto escolar é algo que incomoda. Por outro lado, todos expressaram o incômodo relacionado ao clima não tão harmonioso entre os colegas de trabalho. Chiavenato (2009) defende que a falta de respeito ao outro e a impetuosidade nas relações interpessoais perpassam a falta de diálogo. Ao ingressar em uma organização, as pessoas buscam a satisfação de algumas necessidades pessoais e, em troca, estão dispostas a incorrer em certos custos ou a fazer certos investimentos e esforços, sendo que o equilíbrio organizacional está justamente "na troca proporcional de incentivos e contribuições entre as partes" (Luck, 2014, p. 23).

Diante do exposto, a escola, como instituição reprodutora de saberes, deve administrar ações voltadas para a boa convivência de todos que compõem o ambiente, visto que vivemos em um período em que somos governados por ações pouco efetivas, no que diz respeito ao desmonte da educação, às ameaças sofridas pelas instituições democráticas, aos ataques a qualquer forma de resistência e de luta, às universidades e aos indivíduos em geral. Logo, se esse espaço vier a reproduzir, por meio da gestão, o que vivenciamos no governo atual, o que será dos familiares, educandos e dos funcionários em geral? Libâneo (2013) assevera que toda instituição escolar deve assumir responsabilidades que ultrapassem questões administrativas e burocráticas, admitindo sentido à função de prática educativa, uma vez que cumprem o papel de transmitir valores e atitudes, influenciando em aprendizagens e em modos de agir dos sujeitos que ali pertencem.

Em consonância com os pressupostos apresentados, voltados à compreensão do que mais incomodava os profissionais da instituição analisada, solicitamos a exposição dos maiores desafios enfrentados na escola:

O maior desafio está sendo viver este período atual, no cenário de um pandemia que afeta milhões de família. Consequentemente, os estudantes estão ficando imensamente prejudicados. Dessa forma, fazer com que o ensino chegue aos lugares mais remotos e beneficie estes estudantes está sendo o principal desafio. Mas temos tido bons resultados. De 988 alunos atualmente matriculados em nossa escola, somente $2,3 \%$ não teve acesso aos materiais do REANP (Regime de Estudo não presencial). Ainda estamos em busca de atender $100 \%$ de nossa escola ao flexibilizar prazos e metodologias ( $\mathrm{S}-$ Luna).

Resistência dos professores em aceitar novas abordagens pedagógicas. Administrar conflitos pessoais de alunos com familiares e que repercute no seu relacionamento com outras pessoas dentro da escola ( $S$ - Bruna).

A pandemia, as incertezas e a insegurança que esse momento trouxe para todos (familiares, alunos e funcionários) (G - Aurora).

O maior desafio que já enfrentei na profissão está sendo justamente esse período que estamos vivenciando da Covid-19. Somos exigidos ao máximo pelo Estado e parece que nada que fazemos é o suficiente, além do emocional estar abalado, temos a cobrança de pais e alunos que acreditam que a culpa dos alunos não estarem acompanhando o ensino remoto pelo REANP é nossa ( $S$ - Lara).

Abandono familiar a uma estudante. Histórico familiar de rejeição à existência dela. Foi difícil ter que mostrar para ela que ela é importante e merece ser valorizada (VG - Ana).

Atingir e criar uma parceria efetiva com o corpo docente, principalmente com foco na disciplina dos educandos (VG -Naldo).

Os desafios apresentados são pautados nas relações conflituosas entre familiares e docentes, sendo intensificadas algumas dificuldades durante a pandemia. A partir dos relatos 
obtidos, depreendemos a falta de diálogo sobre as necessidades dos indivíduos, pois soluções e alternativas poderiam abrolhar de uma comunicação simplificada.

Em relação ao momento de pandemia, é inegável o fato de que as condições econômicas podem imprimir certa privação de direitos, realidade comum para muitas crianças e famílias brasileiras e que, supostamente, foi agravada na atual conjuntura. Os dados do UNICEF (2019) esclarecem um pouco sobre essa situação, mesmo esses sejam anteriores ao Covid-19 - grande parte das crianças excluídas do direito à educação reside em periferias de grandes centros urbanos, sendo que $53 \%$ desse grupo vive em domicílios com renda per capita de até meio salário mínimo. Tais informações confirmam a necessidade de evidenciar reflexões e estudos relacionados à responsabilidade e ao acolhimento social dos cidadãos, tanto na escola como na sociedade, uma vez que, no Brasil, as lutas e as dificuldades ainda afloram de forma injusta e desigual.

Nessa perspectiva, foram ressaltadas propostas importantes para se manter um bom relacionamento e uma aproximação saudável dos familiares dos educandos, sendo demonstradas da seguinte maneira no discurso da equipe gestora:

Diálogo sempre com as famílias para nos ouvirem e nós também escutarmos as suas propostas. Penso que um canal específico de comunicação com essa famílias, como grupo no WhatsApp ou outra rede social, seria de suma importância ( $G$ - Aurora).

O principal passo é o diálogo. Ao escutar o que os pais estão nos apontando, bem como tentar nos colocar na situação deles, faz que com demonstremos uma empatia com a situação. Ou seja, não deve existir nos dias de hoje a figura de um profissional autoritário, que impõe suas verdades a qualquer custo, pois estamos todos no mesmo barco, em busca de uma educação de qualidade para nossos alunos ( $S$ - Luna).

Acredito que estar sempre em contato com os familiares é algo importante para deixá-los informados sobre a vida escolar do seu filho ( $S$ - Bruna).

Criar espaços onde os pais se sintam como parte integrante da comunidade escolar ( $\mathrm{S}$ - Lara).

Acredito que todas as propostas possíveis já foram feitas as famílias, agora elas que deveriam valorizar seus filhos e buscarem participação na vida deles (VG- Ana).

A postura da escola deve mudar e deixar de chamar os pais para resolver problemas e criar vínculos positivos de confiança e parceria (VG - Naldo).

Entre as respostas obtidas, somente a vice-gestora, Ana, parece estar desmotivada quanto às possíveis melhorias no âmbito escolar, delegando compromisso e responsabilidade às famílias dos educandos, por acreditar que todas possibilidades já foram colocadas em prática.

Outra sugestão dos profissionais seria ter um canal de comunicação específico para atender as famílias. Inclusive, esse tipo de iniciativa poderia facilitar o contato e a troca de informações. Isso evidenciou a importância dessa alternativa sugerida pela gestora Aurora. Salientamos, ainda, a parceria e o envolvimento da família por meio do diálogo, conforme colocado pelo vice-gestor Naldo, que frisou o lado positivo das relações interpessoais.

É válido pontuar que apenas quatro integrantes da equipe gestora - sendo três supervisoras (Luna, Bruna e Lara) e o vice-gestor (Naldo) - responderam todas as questões abertas oferecendo explicações completas. Os demais sujeitos participantes não elaboraram comentos substanciais ${ }^{2}$ e, por isso, não realizamos a transcrição dessas respostas.

\footnotetext{
${ }^{2}$ Limitados entre uma e, no máximo, três palavras, não abarcando uma resposta reflexiva sobre a questão proposta.
} 
Ao analisarmos os elementos que compõem o universo pesquisado (instituição escolar), caracterizado pela heterogeneidade cultural e pela gestão democrática, foi corroborado que a equipe gestora constitui o principal elo entre os membros escolares, buscando manter o bom andamento da instituição. Contudo, não se pode olvidar dos conflitos profissionais, tais como competição, falta de coletividade e de companheirismo entre colegas, algo que não está sendo trabalhado à luz dos princípios que respaldam o setor. Nesse interim, é importante que esse grupo vise privilegiar, em suas práticas, a superação de conflitos pessoais na atuação, a fim de possibilitar mudanças e reflexões sobre vínculos e relações, comtemplando a escola como parte indissociável do âmbito social.

As proposições formuladas no questionário foram baseadas nos princípios norteadores do cargo de gestor e de especialistas da educação básica, com a finalidade de identificar situações conturbadas e permitir a proposição de soluções/alternativas que sejam do interesse de todos que compõem o ambiente escolar, em prol do bem-estar coletivo e da eficácia do processo de ensino e aprendizagem. Assim, juntos, e de forma solidária, podermos criar alicerces resistentes a influências inalienáveis do referido contexto.

\section{CONCLUSÃO}

Durante a pesquisa do tema concernente, verificamos que a equipe gestora, em geral, admite a essencialidade da participação familiar no âmbito institucional. Todavia, os achados da presente pesquisa evidenciaram situações conflituosas entre os membros escolares e as familiares dos educandos, o que demonstra a necessidade constante de debates escolares sobre as relações interpessoais, mesmo com a possibilidade de incitar polêmicas e causar confrontos de ideias, haja vista a necessidade de se colocar em prática os princípios norteadores democráticos, por meio da comunicabilidade.

Percebemos que as questões levantadas pelos profissionais da gestão circunscrevem a realidade de uma sociedade que se adentra em muros escolares. Muito do que almejamos, produzimos e o modo como encaramos as situações diárias se sobressaem, de alguma forma, em nossas atitudes, fato que tem se tornado evidente nos ambientes de trabalho, nesse caso, o escolar.

$\mathrm{Na}$ tentativa de compreender o olhar da equipe gestora em relação às famílias, observamos que todos os respondentes concordam que a participação familiar é baixa e não satisfatória no âmbito escolar. Segundo os profissionais, as famílias estão negligenciando os estudos e os cuidados com os filhos na escola, principalmente durante o período de pandemia. Contudo, essa suposição coloca todos em um mesmo patamar, o que acaba, de certo modo, influenciando negativamente todos aqueles que compõem esse espaço.

Nesse sentido, reiteramos, também ao longo do estudo, que tanto a família como a escola passaram por transformações, cabendo à instituição, por meio da gestão, encontrar soluções para o impasse que se estabelece entre os envolvidos, procurando atraí-los para uma parceria saudável, sem resultar em um modelo "ideal".

Observamos também que as ações dos profissionais estão submetidas a certas atitudes, que contraria os princípios norteadores do cargo da gestão, visto que eles parecem subestimar o diálogo e a dissolução de conflitos por meio da comunicabilidade. Consequentemente, a realização das atividades feitas por meio do conformismo e sem interlocução entre os envolvidos gera uma ambientação negativa, o que poderá suscitar consequências drásticas na vida de todos os envolvidos.

Nesse sentido, a gestão escolar deve compreender que, quando não se atinge o principal objetivo de ensino em prol da coletividade, é preciso adaptar a postura, redirecionando práticas sociais e educacionais por meio do uso do diálogo, com a consciência que a transformação pode ser lenta, mas o importante é que ela seja concreta. 
A função da escola é distinta do papel da família em relação ao desenvolvimento do(a) aluno(a), mas ambas representam parcelas significantes, portanto é de fundamental importância e necessária a reflexão sobre a participação da família na escola, bem como, na mesma proporção, o papel da escola para a construção desse desenvolvimento, para a compreensão do contexto, considerando a influência que estes partícipes estabelecem na vida acadêmica dos educandos.

Portanto, evidenciamos a necessidade de novas pesquisas que abordem o vínculo entre escola e família, sendo a gestão escolar o principal mecanismo desse contato que se perpassa no espaço escolar. Mesmo com a "névoa" que paira os institutos educacionais e acadêmicos no Brasil, cujos mandatários atuais tentam eliminar as mentes mais críticas, reforçamos o principal objetivo das ciências humanas, que é continuar seguindo o percurso do conhecimento para fomentar possiblidades de um futuro melhor.

Contribuições dos Autores: Souza, V. E. B.: concepção e desenho, aquisição de dados, análise e interpretação dos dados, redação do artigo, revisão crítica relevante do conteúdo intelectual; Mello, R. M. A. V.: concepção e desenho, aquisição de dados, análise e interpretação dos dados, redação do artigo, revisão crítica relevante do conteúdo intelectual; Barreto, M. L. M.: concepção e desenho, aquisição de dados, análise e interpretação dos dados, redação do artigo, revisão crítica relevante do conteúdo intelectual. Todos os autores leram e aprovaram a versão final do manuscrito.

Aprovação Ética: Não aplicável.

Agradecimentos: Os autores agradecem o financiamento para a realização deste estudo fornecido pela FAPEMIG (Fundação de Amparo à Pesquisa do Estado de Minas Gerais - Brasil).

\section{REFERÊNCIAS}

Antunes, R. (2020). Meta é sairmos vivos dessa crise, metas do teletrabalho na pandemia. Sintrajud, São Paulo. https://www.sintrajud.org.br/meta-e-sairmos-vivos-dessa-crise-afirma-sociologo-contra-metas-do-teletrabalho-napandemia/

Bourdieu, P. (1983). Questões de Sociologia. Rio de Janeiro - RJ: Editora Marco Zero.

Bourdieu, P., \& Passeron, J. C. (1992). A Reprodução. Rio de Janeiro: Francisco Alves.

Bourdieu, P. (2001). Razões práticas: sobre a teoria da ação. 3 ed. Campinas: Papirus.

Braga, R. (2020). Covid-19 e avanço tecnológico: nasce um outro mundo do trabalho. Entrevistas especiais com Ruy Braga Neto e Rafael Grohmann. Combate Racismo Ambiental. https://racismoambiental.net.br/2020/05/04/covid-19e-avanco-tecnologico-nasce-um-outro-mundo-do-trabalho-entrevistas-especiais-com-ruy-braga-neto-e-rafaelgrohmann/

Braunert, M. B., \& Bridi, M. A. (2020). Home-office e a precarização do servidor público. Outras palavras - jornalismo de profundidade e pós-capitalismo. http://www.dmtemdebate.com.br/o-teletrabalho-no-setor-publico-veio-paraficarl

Brasil. (1996). Lei de Diretrizes e Bases da Educação Nacional: no 9394/96. Senado Federal. Brasília.

Chiavenato, I. (2009). Gestão de Pessoas. São Paulo.

Cury, C. R. J. (2002). Gestão democrática na educação: exigências e desafios. Revista Brasileira de Política e Administração da Educação, 18, 163-174.

Gil, A. C. (2008). Como elaborar projetos de pesquisa. São Paulo: Atlas.

Gonçalves, L. A. O., \& Sposito, M. P. (2002). Iniciativas públicas de redução da violência escolar no Brasil. Cadernos de Pesquisa, 115, 101-138.

Instituto Brasileiro de Geografia e Estatística. (2019). Pesquisa Nacional por Amostra de instituições de Ensino Superior. Rio de Janeiro.

Libâneo, J. C. (2013). Organização e gestão da escola: teoria e prática. Goiânia. São Paulo. Ed. Heccus.

Libâneo, J. C., \& Pimenta, S. G. (2002). Formação dos profissionais da educação: visão crítica e perspectivas de mudança. In: Pimenta, S. G. (Org.). Pedagogia e Pedagogos: caminhos e perspectivas. São Paulo: Cortez, p. 35-43. 
Luck, H. (2014). Liderança em gestão escolar. Petrópolis, RJ: Vozes.

Nogueira, M. A. (2006). Família e escola na contemporaneidade: os meandros de uma relação. Educ. Real. 31(2), 155170.

Nogueira, C. M. M., \& Nogueira, M. A. (2002) A sociologia da educação de Pierre Bourdieu: limites e contribuições. Educação \& Sociedade, 23(78), 15-36.

Oliveira, A. C. P. (2015). As relações entre Direção, Liderança e Clima Escolar em escolas municipais do Rio de Janeiro. Tese (Doutorado) - Pontifícia Universidade Católica do Rio de Janeiro, Departamento de Educação.

Oliveira, A. C. P., \& Paes de Carvalho, C. (2018). Gestão escolar, liderança do diretor e resultados educacionais no Brasil. Revista Brasileira de Educação, 23, e230015.

PARO, V. H. (2011). Progressão continuada, supervisão escolar e avaliação externa: implicações para a qualidade do ensino. Revista Brasileira de Educação, 16(48), 695-716.

Saffioti, H. I. B. (2004). Gênero, patriarcado, violência. São Paulo: Editora Fundação Perseu Abramo.

Schilling, F. (2004). A sociedade da insegurança e a violência na escola. São Paulo: Moderna.

Setton, M. G. (2002). Família, escola e mídia: um campo com novas configurações. Revista Educação e pesquisa, 28(1), 107-116.

Setton, M. G. J. (2010). Uma introdução a Pierre Bourdieu. http://revistacult.uol.com.br/home/2010/03/umaintroducao-a-pierre-bourdieu/

Sposito, M. P. (2002). Iniciativas públicas de redução da violência escolar no Brasil. Cadernos de Pesquisa, 115, 101139.

Szymanzki, H. (2011). A relação família/escola: desafios e perspectivas. Brasília: Líber Livro.

Trindade, L. M., Pinto, L. B. F., Cavalcante, M. N., \& Almeida, R. S. (2015). Projeto Político Pedagógico: a gestão e a função social da escola para a comunidade. Revista Científica Semana Acadêmica, 69(1), 1-16.

Unicef. (2019). 30 Anos da Convenção Sobre os Direitos da Criança: Avanços e desafios para meninas e meninos no Brasil. São Paulo: UNICEF.

Recebido: 21 de Junho de 2021 | Aceito: 12 de Setembro de 2021 | Publicado: 18 de Outubro de 2021 